\title{
A APRENDIZAGEM EMPREENDEDORA NO CONTEXTO DA EDUCAÇÃO FORMAL, INFORMAL E NÃO-FORMAL: TEORIAS E INTERPRETAÇÕES RELACIONADAS ÀS PRÁTICAS DIDÁTICO-PEDAGÓGICAS
}

\section{THE DEVELOPMENT OF ENTREPRENEURIAL COMPETENCE INYOUNG PEOPLE: THE BRAZILIAN AND ITALIAN CONTEXT}

\author{
Jocilene Gadioli de Oliveira, Elena Marescotti
}

Universidade de Ferrara

E-mail: jocilenegadioli@hotmail.com, elena.marescotti@unife.it

\section{Resumo}

O presente artigo faz parte de uma pesquisa de doutorado, tendo como objetivo identificar e analisar as práticas de formação de competências empreendedoras em diferentes contextos (formal, não-formal e informal). O caminho metodológico escolhido foi pesquisa de campo, na realização de cinco entrevistas semi-estruturadas nos municípios de Vila Velha e Vitória (ES). Os dados coletados foram organizados e deles emergiu que as práticas citadas correspondem à educação formal e não-formal. Além disso, os entrevistados descreveram aspectos do empreendedorismo e do empreendedor ligados ao conceito de empresa. Conclui-se que a aprendizagem empreendedora visa o desenvolvimento do indivíduo como pessoa, de competências transversais para o exercício de uma cidadania ativa e de uma nova mentalidade.

Palavras-chave: aprendizagem empreendedora. educação formal, informal e não-formal. competências empreendedoras. empreendedorismo.

\begin{abstract}
This article is part of a PhD research, with the main objective to identify and analyze the training practices of entrepreneurial competences in different contexts (formal, non-formal and informal). The methodological path chosen was field research in achieving five semi-structured interviews in the cities of Vila Velha and Vitória (ES). The collected data were organized and them emerged that the practices cited correspond to formal and non-formal education. In addition, respondents described aspects of entrepreneurship and enterprising linked to the concept of business. It concludes that the entrepreneurship learning aims to develop the individual as a person, horizontal skills for the exercise of active citizenship and a new mindset.
\end{abstract}

Keywords: entrepreneurship. learning formal, non-formal and informal education. entrepreneurship competencies. entrepreneurship. 


\section{INTRODUÇÃO}

A pesquisa de doutorado buscou identificar e analisar as práticas de formação de competências empreendedoras nos jovens em diferentes contextos. Neste artigo são abordados os resultados das análises no território brasileiro, nos municípios de Vila Velha e Vitória, localizados no Estado do Espírito Santo.

A escolha desse objeto de estudo é justificada à luz da crescente importância que a formação de uma cultura empreendedora nos jovens está tomando em nosso mundo contemporâneo, para que eles possam lidar com consciência as futuras escolhas educacionais e profissionais. Assim, por meio dessa pesquisa, foi possível descrever algumas percepções com relação ao empreendedorismo, analisar conceitos relacionados ao desenvolvimento de competências empreendedoras, assim como descrever práticas didático-pedagógicas que visam promover a aprendizagem empreendedora nos jovens, em particular modo, nos estudantes universitários.

Para a Comissão Europeia o "espírito empreendedor é a capacidade de uma pessoa para transformar ideias em ação. Os programas e módulos de empreendedorismo oferecem aos estudantes as ferramentas para pensar criativamente e resolver problemas de modo eficaz" (Commissione Europea, 2009, p. 10).

No Brasil, enfatiza-se a importância do tema do desenvolvimento de competências empreendedoras, especialmente na educação e na formação, para responder às demandas do mercado de trabalho, de modo a promover o crescimento sustentável dos Países envolvidos. Neste contexto, a integração entre escola, universidade e mercado de trabalho é crucial não só para o desenvolvimento da economia de um país através de novas empresas ou de empresas mais inovadoras, mas, sobretudo na perspectiva de uma recaída sobre os jovens em relação ao crescimento de uma cultura empreendedora. Esta abordagem tem como objetivo o desenvolvimento de jovens mais ativos, mais conscientes de seus próprios recursos (potencial), mais autônomos e capazes de propiciar mudanças, conhecimentos e aprendizagens ao longo da vida. Para Lopes (2010) os países mais desenvolvidos têm uma cultura empreendedora mais forte e têm sistemas bem estruturados e que visam desenvolver o espírito empreendedor das pessoas de uma forma sustentável. 
Além disso, através da pesquisa foi possível estudar tais práticas em diferentes contextos, especificamente o tema do empreendedorismo na aprendizagem formal e não-formal, e também evidenciar como as competências empreendedoras são desenvolvidas através de algumas experiências com a aprendizagem informal, considerando aspectos relativos ao reconhecimento e validação das competências.

Para a Comissão Européia (Commissione Europea, 2012), a aprendizagem formal é realizada em um contexto organizado e estruturado; a aprendizagem não-formal é realizada mediante atividades planejadas (em termos de objetivo e de tempo para a aprendizagem) com qualquer forma de suporte à aprendizagem; aprendizagem informal é o resultado das atividades da vida quotidiana ligadas ao trabalho, à família e ao tempo livre, além de não ser estruturada em termos de objetivos, tempo ou recursos. A aprendizagem formal passa pela educação formal, com objetivos claros e precisos, prevalentemente através das escolas e das universidades. A educação não-formal não precisa seguir necessariamente um sistema sequencial e hierárquico, pode ter duração variável com presença ou não de um certificado na conclusão de curso. Já a aprendizagem informal, pode ser realizada em qualquer lugar, indiferentemente do tempo e da experiência; é uma abertura à sociedade do conhecimento, onde todo tempo é tempo de aprender (Gadotti, 2005).

Nesse contexto, a valorização, o reconhecimento e a validação das competências ganham destaque em uma abordagem por competências, centralizada na aprendizagem do indivíduo. Os conhecimentos, as habilidades e as capacidades pessoais formam as competências do indivíduo que ao passar através da educação formal e não-formal podem ser avaliadas e certificadas. Já as aprendizagens informais são ainda de difícil certificação ou são certificadas de maneira superficial e parcial, não valorizando e não conscientizando as reais capacidades do indivíduo (Oliveira, 2015). Existem várias discussões sobre a possibilidade de descrever, em termos claros e precisos, os resultados da aprendizagem, quais são os conhecimentos, as habilidades e, em última instância, as capacidades pessoais que devem ser tidos em consideração na avaliação e na certificação (Lum, 2004). Assim, a União Europeia desenvolveu vários projetos na intenção de poder avaliar e certificar as aprendizagens do individuo ao longo da vida e em diferentes contextos, em particular modo, referindo-se às competências empreendedoras; o modelo Entrepreneurship Education é um instrumento para a certificação das aprendizagens empreendedoras e está sendo experimentado 
pelos Países europeus. Neste modelo de desenvolvimento e certificação de competências empreendedoras foi determinado um quadro de atitudes, conhecimentos e capacidades empreendedoras a serem seguidas pelos sistemas de educação e de formação. O que está em fase de desenvolvimento é como tais comportamentos e capacidades podem ser avaliados, tendo em vista que esse tipo de aprendizagem nem sempre passa pelos canais formais de educação (European Commission, 2013a). Outra observação é feita considerando os processos de desenvolvimento do indivíduo, que se transformam e evoluem de acordo com um processo histórico (tempo cronológico) e outras variáveis que podem influenciar a aquisição ou não de uma determinada competência, ou seja, aspectos como vontade e disponibilidade em aprender, recursos apropriados, experiências pregressas, aspectos físicos, cognitivos e etc. (Oliveira, 2015). Todo esse interesse em desenvolver modelos, práticas e instrumentos que possam desenvolver uma aprendizagem empreendedora faz parte da estratégia de tornar o indivíduo mais preparado não só para o mercado de trabalho, mas para a vida em sociedade. No Brasil, a Educação Empreendedora propõe práticas pedagógicas que visam à ruptura de um modelo estático de aprendizagem, propiciando reflexões e a aplicação dos saberes na forma de ações transformadoras (Sebrae, 2015).

Na verdade, o esforço em concentrar a instrução e a formação no desenvolvimento de habilidades transversais, isto é, na capacidade de pensar em modo crítico, na capacidade em resolver problemas e em ter iniciativa e etc., faz parte da formação geral que as escolas e as universidades deveriam fornecer, dando a todos os indivíduos a possibilidade de desenvolver estratégias e instrumentos para iniciar um caminho de crescimento, verso a um papel conotado de consciência, autonomia e responsabilidade (Marescotti, 2013). Assim, quando se fala de aprendizagem empreendedora, refere-se aos conhecimentos e as habilidades de amplo significado, que prefigura e alarga o sentido de tudo o que se refere ao empreendedorismo, ou seja, a criatividade, a iniciativa, a responsabilidade de escolha, poder de decisão e outras, que fazem pensar na metáfora ser empreendedor de si mesmo (Marescotti, 2013).

Mas, muitas vezes o que acontece, é que muitas práticas didático-pedagógicas apoiam o desenvolvimento de competências empreendedoras ligadas prevalentemente à área técnica ou de empresa, ou seja, com conteúdos de empresa ou de mercado (Oliveira, 2015). A tentativa de aproximar o sistema de educação e de formação ao mercado de trabalho é um tema muito 
discutido em muitos Países, sobretudo, com o agrave de crise econômica mundial, mas existem também aqueles que defendem uma cultura de escola que não se coloque a serviço das tendências político-econômicas (Marescotti, 2013).

Outro ponto de reflexão é sobre a formação dos professores, que nem sempre recebem recursos e formação necessária para implementar tais práticas didático-pedagógicas. O professor tem um papel fundamental na realização das ações ou práticas empreendedoras, mas é necessário que o mesmo esteja preparado, pois na maioria nas vezes não existe uma disciplina específica, mas uma forma de ensinar em que a aprendizagem é experimental e trabalha por meio de projetos didáticopedagógicos. "Para desenvolver uma atitude empreendedora, os professores precisam de uma vasta gama de competências relacionadas com a criatividade e com o empreendedorismo" (European Commission, 2013b); essa abordagem exige que a escola e a universidade promovam um ambiente onde a criatividade e o correr riscos possam ser incentivados, os erros possam ser valorizados como uma oportunidade de aprendizagem. Para apoiar a teoria de que os jovens se sentem mais preparados, mais conscientes e em poder de exercer uma cidadania ativa, algumas universidades, institutos e organizações do setor público e privado organizam cursos, capacitações e projetos que são desenvolvidos em todo o país. 


\section{PESQUISA DE CAMPO}

Para alcançar o objetivo desta pesquisa foram realizadas cinco entrevistas para coletar informações, conceitos e práticas relacionadas ao desenvolvimento das capacidades empreendedoras nos jovens com a participação de universidades, instituições de pesquisa, organizações do setor privado, órgãos públicos e de formação profissional.

O instrumento qualitativo é uma entrevista semi-estruturada, que oferece um roteiro que ilustra as questões que precisam ser abordadas durante o encontro, veja a tabela a seguir.

Tabela 1. Argumentos e esquema para a realização das entrevistas.

\begin{tabular}{|c|c|}
\hline Areas & Variáveis \\
\hline $\begin{array}{l}\text { Acolhimento } \\
\text { Análise de contexto }\end{array}$ & $\begin{array}{l}\text { 1. Qual é o seu papel e qual a sua funçô dentro } \\
\text { dessa estrutura? Há quanto tempo você realiza esse } \\
\text { papel e resliza tais finçôes? } \\
\text { 2. Quais são os serviços que sào prestados pela sua } \\
\text { estrutura? } \\
\text { 3. Qual é o seu público? }\end{array}$ \\
\hline $\begin{array}{l}\text { O empreendedor } \\
\text { o desenvolvimento de competências } \\
\text { empreendedoras }\end{array}$ & 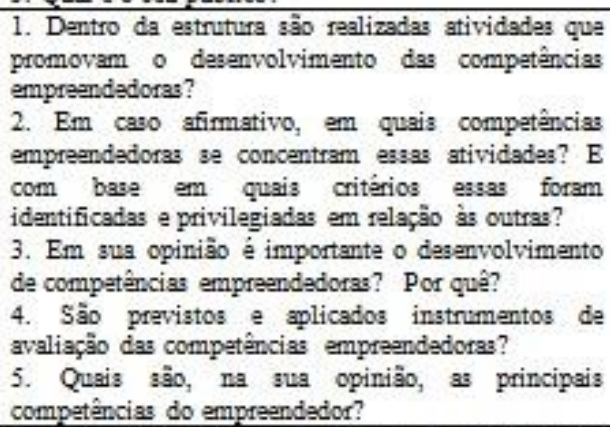 \\
\hline $\begin{array}{l}\text { O empresndadorismo } \\
\text { Práticas de desenvolvimento do empreendedorismo } \\
\text { As competências do empreendador }\end{array}$ & 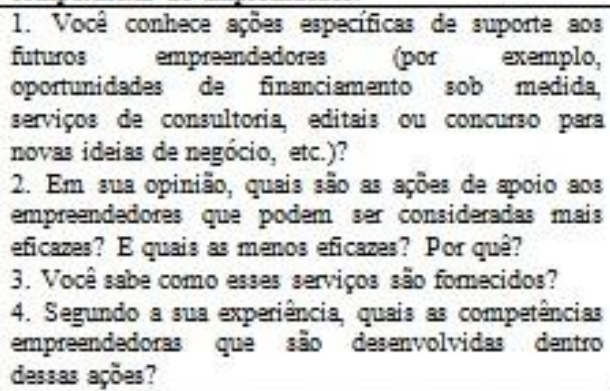 \\
\hline $\begin{array}{l}\text { A certificaçâo das aprendizagens } \\
\text { Acordos/programas com o meio acadêmico }\end{array}$ & 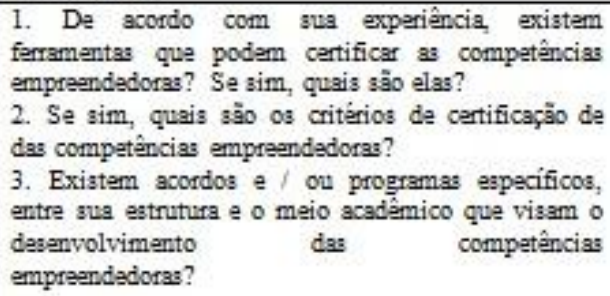 \\
\hline
\end{tabular}

Fonte: dados da pesquisa. 
A análise dos dados das entrevistas foram realizadas com o apoio do software NVIVO 10 - Nonnumerical Unstructured Data Indexing, Searching and Theorizing Vivo (licenciado para uso no Kings College de Londres), com o objetivo de preparar e organizar os dados para análise, tais como a criação de estruturas e categorias durante o processo de codificação de dados e de gestão das fontes de informação.

As entrevistas foram realizadas seguindo alguns argumentos:

- $\quad$ Análise do contexto;

- Empreendedor e do desenvolvimento de competências empreendedoras;

- Empreendedorismo, práticas de desenvolvimento do empreendedorismo e as competências do empreendedor;

- Certificação de aprendizagem e de acordos/programas com o meio acadêmico.

A técnica de análise qualitativa utilizada é a de conteúdo e considera os elementos do contexto, casos individuais ou marcantes, a frequência de certos conceitos, opiniões, etc. Os entrevistados que foram convidados a participar têm uma conexão com o tema de pesquisa. Eles trabalham dentro de estruturas que de alguma forma promovem o desenvolvimento de competências empreendedoras e, portanto, têm algumas características em comum: oferecem serviços para ajudar os jovens empreendedores e promovem o espírito empreendedor entre os jovens.

As entrevistas foram gravadas e, numa fase posterior, foram transcritas na íntegra. A única exceção foi um entrevistado que não concedeu autorização para registro, publicação e tratamento dos dados. Os entrevistados eram livres para responder, para exprimir opiniões, para avaliar e também para adicionar outras ideias não abrangidas pelo entrevistador. Em média, as entrevistas duraram entre 40 minutos e 60 minutos. Então, a partir das entrevistas, que é considerada uma fase exploratória, foram organizados e analisados os dados usando o software NVIVO. 


\section{EVIDÊNCIAS EMPÍRICAS: PRÁTICAS DIDÁTICO-PEDAGÓGICAS NO DESENVOLVIMENTO DE COMPETÊNCIAS EMPREENDEDORAS}

Para descrever aspectos que caracterizam o fenômeno do empreendedorismo e identificar conceitos e práticas que relativas ao desenvolvimento de competências empreendedoras em jovens, estudantes universitários em particular, foram realizadas cinco entrevistas.

$\mathrm{Na}$ categoria Analise de contexto é emerso que, em todos os institutos/organismos onde trabalham os entrevistados, existem atividades, projetos, serviços ou programas destinados ao desenvolvimento do empreendedorismo nos municípios de Vitória e Vila Velha, localizados no estado do Espírito Santo; essa foi a premissa considerada necessária na escolha dos entrevistados. A segunda observação é que a maioria dessas instituições focam em pequenas e médias empresas, em empreendedores individuais ou trabalhadores autônomos e/ou jovens que têm, pelo menos, uma ideia de negócio. Das entrevistas realizadas, apenas dois entrevistados declararam ter projetos que desenvolvem competências empreendedoras nos jovens.

Quanto às atividades relacionadas ao desenvolvimento de competências empreendedoras (realizadas ou de conhecimento dos entrevistados) e à respectiva descrição (dada pelos entrevistados) das competências necessárias para uma pessoa se tornar empreendedora, foi verificado se as competências citadas são desenvolvidas nos projetos, atividades ou programas descritos pelos entrevistados. Na próxima tabela podem ser observados os dados referentes a esta análise. 
Tabela 2. Atividades e competências empreendedoras X Competências do Empreendedor.

\begin{tabular}{|c|c|c|c|}
\hline Entrevistados & $\begin{array}{c}\text { A: Atividades } \\
\text { Relacionadas com o } \\
\text { desenvolvimento de } \\
\text { competências } \\
\text { empreendedor as }\end{array}$ & $\begin{array}{l}\text { B: Competências do } \\
\text { empreendedor }\end{array}$ & $\begin{array}{l}\text { C: Competências } \\
\text { desenvolvidas nas } \\
\text { atividades citadas }\end{array}$ \\
\hline Entrevistado 1 & $\begin{array}{l}\text { Economia Solidária; } \\
\text { Programa Incluir; } \\
\text { Comércio Total; } \\
\text { Centro do } \\
\text { Empreendedor; Plano } \\
\text { Capixaba de Cultura } \\
\text { Exportadora; } \\
\text { SEBRAE TEC; } \\
\text { Banco Comunitário; } \\
\text { Incubadoras, uma série } \\
\text { de mini clusters; } \\
\text { Inclusão Produtiva. }\end{array}$ & $\begin{array}{l}\text { Planejamento e gestão } \\
\text { são fundamentais. }\end{array}$ & $\begin{array}{l}\text { Visão de negócios; } \\
\text { Marketing; } \\
\text { conhecimento na área de } \\
\text { finanças; na área de } \\
\text { controle de estoque; } \\
\text { como exportar, para } \\
\text { onde, os mercados, ou } \\
\text { seja, dizendo um pouco, } \\
\text { falando um pouco sobre } \\
\text { esta questão, de como } \\
\text { que é o processo de } \\
\text { exportação; na área de } \\
\text { exportação na parte de } \\
\text { inovação e tecnologia. }\end{array}$ \\
\hline Entrevistado 2 & $\begin{array}{c}\text { Núcleo de Prática } \\
\text { Jurídica; Clínica de } \\
\text { Psicologia; Clínica de } \\
\text { Odontologia; } \\
\text { atendimentos de } \\
\text { Enfermagem; ações } \\
\text { específicas oferecidas } \\
\text { para as comunidades do } \\
\text { entorno da nossa } \\
\text { instituição; Unidade de } \\
\text { Gestão e Negócios; } \\
\text { parceria com o } \\
\text { SEBRAE; estágio } \\
\text { obrigatório; realização } \\
\text { de oficinas. }\end{array}$ & $\begin{array}{l}\text { Tem que ter iniciativa; } \\
\text { tem que ser proativo; } \\
\text { tem que enxergar } \\
\text { oportunidades; enxergar } \\
\text { o além; alcançar as suas } \\
\text { metas. }\end{array}$ & $\begin{array}{l}\text { Iniciativa; ser proativo; } \\
\text { enxergar oportunidades } \\
\text { dentro da área dele e a } \\
\text { inserção da área dele } \\
\text { dentro da sociedade. }\end{array}$ \\
\hline Entrevistado 3 & $\begin{array}{c}\text { Palestras nas } \\
\text { universidades em } \\
\text { disciplinas ligadas ao } \\
\text { Empreendedorismo; } \\
\text { Jr Archivement; } \\
\text { Jovem empreendedor } \\
\text { Rural; } \\
\text { Nosso Crédito. }\end{array}$ & $\begin{array}{l}\text { Capacidade de } \\
\text { empreender; de se } \\
\text { motivar; ter coragem. }\end{array}$ & $\begin{array}{l}\text { Controle de receitas e de } \\
\text { despesa; gestão da } \\
\text { empresa; montar fluxo } \\
\text { de caixa; saibam fazer } \\
\text { um projeto; } \\
\text { planejamento de longo } \\
\text { prazo para investir; } \\
\text { aumentar a } \\
\text { competitividade. }\end{array}$ \\
\hline Entrevistado 4 & $\begin{array}{l}\text { Empretec; Desafio } \\
\text { SEBRAE; Endeavour } \\
\text { que é uma incubadora de } \\
\text { empreendedores; o } \\
\text { SEBRAE lançou um } \\
\text { edital para desenvolver e } \\
\text { capacitar o professor } \\
\text { universitário para } \\
\text { trabalhar com o } \\
\text { empreendedorismo na } \\
\text { sala de aula usando a } \\
\text { metodologia do } \\
\text { SEBRAE. }\end{array}$ & $\begin{array}{l}\text { Ter mais atitude; fazer a } \\
\text { diferença no mercado de } \\
\text { trabalho; um conjunto de } \\
\text { características. }\end{array}$ & $\begin{array}{l}\text { Gestão; competitividade; } \\
\text { noção de } \\
\text { empreendedorismo; } 10 \\
\text { características definidas } \\
\text { pela ONU. }\end{array}$ \\
\hline
\end{tabular}

Fonte: dados da pesquisa.

Todos os entrevistados declararam realizar ou ter conhecimento de projetos, atividades ou programas que promovem a cultura empreendedora nas pessoas, mas observa-se na Tabela 2, que 
a maioria dessas práticas descritas corresponde, prevalentemente, às competências técnicas do empreendedor, que além de serem empreendedores são também empresários (que possuem empresas ou atividades autônomas). Isso quer dizer, que para os entrevistados o conceito de empreendedor está muito ligado ao conceito de empresa e de trabalhador autônomo, diretamente ao mercado de trabalho. De fato, as práticas citadas são para jovens empreendedores, mas que já possuem uma atividade empreendedora ou ao menos que tem uma ideia de negócio.

Outra observação diz respeito às competências necessárias para uma pessoa se tornar empreendedora, declaradas pelos entrevistados, onde somente algumas são desenvolvidas nos projetos ou atividades citadas pelos entrevistados. Além disso, é interessante evidenciar que os entrevistados estão inseridos profissionalmente em instituições/organismos, cuja missão é de desenvolver o empreendedorismo na sociedade.

Através do suporte do software NVIVO foi possível criar um modelo de competências empreendedoras desenvolvidas nas atividades descritas, de acordo com a percepção dos entrevistados.

Tabela 3. Competências do Empreendedor desenvolvidas nas atividades.

\begin{tabular}{|c|c|}
\hline \multicolumn{2}{|c|}{ Competências do Empreendedor desenvolvidas nas atividades } \\
\hline $\begin{array}{c}\text { Modelo integrado de } \\
\text { aprendizagem }\end{array}$ & Brasile \\
\hline Instrumentos & $\begin{array}{c}\text { Empretec(હ) e Jr Archivement (s) (são desenvolvidas } \\
10 \text { atividades) }\end{array}$ \\
\hline Disciplinas & Competências técnicas do empreendedor \\
\hline Extracurricular & Motivação start-up \\
\hline Orientação & Auto-conhecimento \\
\hline Formação & Cultura à exportação \\
\hline
\end{tabular}

Fonte: dados da pesquisa.

É possível observar, na Tabela 3, que os dois instrumentos mais citados pelos entrevistados são desenvolvidos em todo o território brasileiro, e não somente nos municípios indagados. Outra constatação é de que, como disciplina inserida nas universidades, os conteúdos são 
correspondentes às competências de área técnica do empreendedor; e quando são desenvolvidas atividades consideradas extracurriculares, os conteúdos abordam a motivação na criação de empresas.

No que diz respeito às atividades de orientação, mesmo que, desenvolvidas em projetos específicos, ajudam a desenvolver o autoconhecimento dos jovens interessados.

Nas práticas de formação citadas, o objetivo principal é de desenvolver a cultura à exportação dos empreendedores, mas que já atuam no mercado e possuem um negócio. Ao analisar o contexto de proveniência das práticas citadas pelos entrevistados, observou-se que elas derivam dos âmbitos formal e não-formal. Nenhuma prática didático-pedagógica de âmbito informal foi citada, talvez por falta de conhecimento ou até mesmo por não serem reconhecidas, pelos entrevistados, como importantes na vivência e na aprendizagem empreendedora.

Em geral, as competências empreendedoras descritas pelos entrevistados são: Comunicação, Motivação, Coragem, Competências técnicas do setor, Proatividade e Desenvoltura. Outras competências descritas pelos entrevistados são: “... capacidade de empreender, de se motivar"; “... ter coragem"; “... ser proativo"; “... ele tem que perceber o entorno dele, a movimentação da sociedade"; “... quais os valores que a sociedade naquele período tem...”.

Outro dado importante e observado através das transcrições é que o fenômeno do empreendedorismo também está ligado ao mercado de trabalho, ou seja, caracterizado por um mecanismo de inclusão produtiva e social, onde muitas vezes tornar-se empreendedor, significa fugir de situações de pobreza, procurando oportunidade em diferentes áreas.

No entanto, verifica-se uma menor atenção com o desenvolvimento da pessoa e as suas competências, e percebe-se, através das entrevistas, que as competências do empreendedor ligadas ao comportamento são consideradas inatas; além disso, foi evidenciado pelos entrevistados a necessidade de implementar o espírito empreendedor em práticas ativas com o objetivo de diminuir o fenômeno da mortalidade das empresas. 
O fenômeno do empreendedorismo, segundo os entrevistados, é caracterizado:

... Para que o indivíduo se sinta mais seguro nas suas decisões, ter mais atitude e possa fazer a diferença no mercado de trabalho.

... o conceito capixaba e brasileiro de empreendedor são pessoas que estão montando o seu negócio ou que já tem o seu negócio pela de vida inteira.

... no Brasil nós temos uma mortalidade de empresas muito grande e alta, nós tínhamos ou temos ainda uma legislação muito pesada no negócio formal.

... o nosso jovem tem que ter iniciativa, tem que ser proativo, tem que enxergar oportunidades dentro da área dele e a inserção da área dele dentro da sociedade.

... A cultura empreendedora é muito importante, porque o profissional hoje, quando ele vai para o mercado, nós pensamos sempre na cultura empreendedora, por ações individuais, mas ele tem que ter essa proatividade ao empreendedorismo, mesmo quando ele está trabalhando em uma empresa, trabalhando inserido num grupo de pessoas, você tem que ter essa cultura empreendedora, você que enxergar o além, quando você dá um passo, o primeiro passo... você tem que estar com o segundo já organizado para você poder alcançar as suas metas e poder evoluir enquanto profissional.

... Para nós o empreendedorismo é uma ferramenta é um mecanismo de porte único de inclusão produtiva.

... Todo ser humano precisa de um empurrão ou instinto do empreendedor

... Empreender é uma possibilidade de oportunidade, e nós acreditamos nisso,... a proposta de trabalhar com empreendedorismo é com a visão de inclusão social, de inclusão produtiva, de emancipação, de redução de violência.

Segundo os entrevistados, o conceito de empreendedorismo se refere ao conceito de empresa, inserindo conceitos concretos de gestão e de crédito.

Alguns construtos resultantes dos estudos efetuados por European Commission (2012) e Lopes (2010) descrevem as características que devem ter ou que deveriam ter uma sociedade orientada ao empreendedorismo, com base no que é indicada nas entrevistas, a próxima tabela elenca as características que identifica qual delas estão presentes no território pesquisado. 
Tabela 4. Elementos que caracterizam uma sociedade empreendedora

\begin{tabular}{|c|c|}
\hline $\begin{array}{c}\text { Elementos que caracterizam uma sociedade } \\
\text { empreendedora }\end{array}$ & $\begin{array}{c}\text { Presente ou não no } \\
\text { território pesquisado }\end{array}$ \\
\hline $\begin{array}{c}\text { Atividades que promovam o desenvolvimento de } \\
\text { competências empreendedoras }\end{array}$ & $\mathrm{X}$ \\
\hline Foco nas pequenas/medias empresas & $\mathrm{X}$ \\
\hline Foco no empreendedor/empresário & $\mathrm{X}$ \\
\hline Foco nos jovens empreendedores & $\mathrm{X}$ \\
\hline Foco na formação empreendedora dos estudantes \\
(universitários) & - \\
\hline Foco no empreendedorismo feminino & - \\
\hline Avaliação das competências do empreendedor & - \\
\hline Certificação das competências do empreendedor & - \\
\hline Acordos ou programas desenvolvidos pelo ensino superior & $\mathrm{X}$ \\
\hline $\begin{array}{c}\text { Reconhece a importância de desenvolver o espírito } \\
\text { empreendedor entre os jovens }\end{array}$ & \\
\hline
\end{tabular}

Fonte: dados da pesquisa

Com a tabela 4, observa-se os elementos que estão presentes nos territórios pesquisados, sintetizando o que foi descrito até o momento com relação às práticas de desenvolvimento das competências empreendedoras. Além disso, ela ilustra alguns pontos que os entrevistados desconhecem, ou que realmente não existem nos territórios de referência.

Um dos entrevistados declarou que "Não tem como certificar o empreendedorismo por ser considerado como um comportamento do indivíduo", o que significa dizer que ele não acredita na possibilidade de certificar competências empreendedoras que as pessoas podem e devem desenvolver. Não existe uma cultura de avaliação e de certificação das competências do empreendedor, segundo os entrevistados, demonstrando um aparente ceticismo a uma possível prática desse tipo.

Com relação a acordos e programas desenvolvidos pelo ensino superior nos territórios pesquisados, existem algumas experiências de colaboração entre alguns setores da sociedade, mas são experiências esporádicas. 


\section{CONSIDERAÇÕES FINAIS}

$\mathrm{O}$ artigo foi realizado descrevendo parte dos resultados de uma pesquisa de doutorado pleno, que tinha o objetivo de delinear o construto do empreendedorismo na sua construção e investigação científica, declinando-o em práticas de desenvolvimento presentes nos territórios indagados e no significado que esse assume na percepção dos estudantes universitários italianos e brasileiros.

Os resultados aqui citados referem-se à realização de entrevistas conduzidas às pessoas que trabalham em instituição que se ocupam em desenvolver o empreendedorismo nos municípios de Vila Velha e Vitória (Espírito Santo).

É interessante observar, que o tema tratado tem origem no desenvolvimento de competências empreendedoras nos jovens, que é uma orientação europeia para criar jovens mais autônomos e conscientes não só do seu papel na sociedade, mas também visando a empregabilidade dos indivíduos. Tais estudos estão ganhando espaço no ambiente internacional, por propiciar crescimento e melhorar a vida do indivíduo e da sociedade.

Nos resultados da pesquisa, vale citar que muitos programas de Educação Empreendedora ou práticas didático-pedagógicas que visam o desenvolvimento das competências empreendedoras, citadas pelos entrevistados, são focalizados na criação de novas empresas e no desenvolvimento de empreendedores, mas que, mesmo assim, já possuem uma atividade ou uma ideia de negócio.

É importante evidenciar que a cultura empreendedora nos países em desenvolvimento, como o Brasil, pode se tornar a chave para sair do seu estado de subdesenvolvimento, transformando o empreendedorismo em uma oportunidade, com introdução de tecnologia e inovação, e não somente para sair de um estado de desemprego para a sobrevivência.

Muitas vezes a cultura de empresa é confundida com uma cultura ao empreendedorismo. As atividades de promoção ao empreendedorismo não podem ser reduzidas a programas de treinamento ou de formação de empresa; é um processo que se destina ao desenvolvimento do sujeito e deve ser realizado em todo o arco da vida. 


\section{AGRADECIMENTOS}

À Coordenação de Aperfeiçoamento de Pessoal de Nível Superior (Capes), pelo apoio dado nos três anos de doutorado pleno no exterior.

Ao Kings College de Londres, pelo acolhimento e interesse no tema de pesquisa.

À Universidade de Ferrara, pela parceria e suporte em todas as atividades de estudo e pesquisa.

\section{REFERÊNCIAS}

COMMISSIONE EUROPEA. Raccomandazione del Consiglio, del 20 dicembre 2012 sulla convalida dell'apprendimento non formale e informale. Disponível em: http://eurlex.europa.eu/LexUriServ/LexUriServ.do?uri=OJ:C:2012:398:0001:0005:IT:PDF>. Acesso em: 2 jul. 2014.

. Competenze chiave per un mondo in trasformazione. Progetto di relazione congiunta 2010 del Consiglio e della Commissione sull'attuazione del programma di lavoro Istruzione e formazione 2010. Roma: 2009. Disponível em: <http://eurlex.europa.eu/lexuriserv/lexuriserv.do?uri=com:2009:0640:fin:it:pdf>. Acesso em: 22 out. 2012.

EUROPEAN COMMISSION. Entrepreneurship Education: A Guide for Educators. Bruxelas: $2013 a$. Disponível em: <http://ec.europa.eu/enterprise/policies/sme/promoting-entrepreneurship/files/education/entredu-manual-fv en.pdf>. Acesso em: 1 jan. 2015.

Communication from the Commission to the European Parliament, the Council, the European economic and social committee and the committee of the regions Entrepreneurship 2020 action plan: reigniting the entrepreneurial spirit in Europe. 2013b. Disponível em: <http://eur-lex.europa.eu/lexuriserv/lexuriserv.do?uri=com:2012:0795:fin:en:pdf>. Acesso em: 1 jan. 2015.

EUROPEAN COMMISSION. Entrepreneurship Education at School in Europe National Strategies, Curricula and Learning Outcomes. Bruxelas: 2012. Disponível em: <http://eacea.ec.europa.eu/education/eurydice/documents/thematic reports/135en.pdf>. Acesso em: 1 jan. 2014.

GADOTTI, Moacir. A questão da educação formal/não formal. Em: Droit à l'éducation: solution à tous les problèmes ou problème sans solution?, 2005. Sion (Suisse). Institut International des Droits de L'enfant (IDE), 18 au 22 octobre 2005.

LOPES, Rose Mary (Org.). Educação Empreendedora. Conceitos, modelos e práticas. Rio de Janeiro: SEBRAE, 2010.

LUM, Gerard. On the Non-discursive Nature of Competence. Educational Philosophy and Theory. Disponível em: <http://onlinelibrary.wiley.com/doi/10.1111/i.1469-5812.2004.085 1.x/pdf>. Acesso em: 16 abr 2014. 
MARESCOTTI, Elena. A quale ruolo "adulto" formerà la scuola? Riflessioni a partire dalla strategia europea Rethinking Education. Studi sulla Formazione, Firenze, Università di Firenze, 2, pp.155170, 2013.

OLIVEIRA, Jocilene Gadioli. Formazione e sviluppo delle competenze imprenditoriali nei giovani: un confronto tra studenti universitari italiani e brasiliani. 2015. 242p. Tesi di Dottorato in Studi Umanistici e Sociali - Studi Umanistici, Università Degli Studi di Ferrara, Italia, 2015.

SERVIÇO BRASILEIRO DE APOIO ÀS MICRO E PEQUENAS EMPRESAS [SEBRAE]. Educação Empreendedora. Estudantes podem desenvolver potencialidades empreendedoras por meio do Programa Nacional de Educação Empreendedora. 2015. Disponível em: < http://www.sebrae.com.br/sites/PortalSEBRAE/Programas/Programa-dissemina-a-educa\%C3\%A7\%C3\%A3o-empreendedora>. Acesso 24 jul. 2013. 